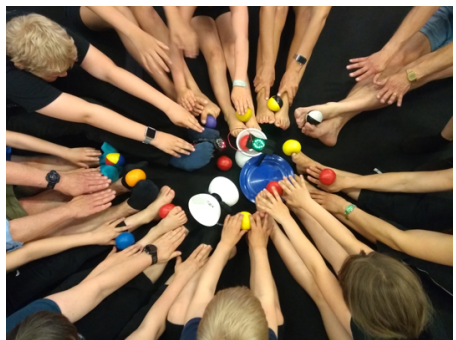

Figure 1: Promotion image from the Super Trouper course

featuring the hand and feet of the participants (children and instructors).

\title{
Super Trouper: The Playful Potential of Interactive Circus Training
}

\section{Elena Márquez Segura \\ Uppsala University \\ Uppsala, Sweden \\ elena.marquez@im.uu.se \\ Annika Waern \\ Uppsala University \\ Uppsala, Sweden \\ Luis Parrilla Bel \\ Uppsala University \\ Uppsala, Sweden \\ Iparrillabel@gmail.com \\ Laia Turmo Vidal \\ Uppsala University \\ Uppsala, Sweden \\ laia.turmo@im.uu.se}

annika.waern@im.uu.se
Permission to make digital or hard copies of part or all of this work for personal or classroom use is granted without fee provided that copies are not made or distributed for profit or commercial advantage and that copies bear this notice and the full citation on the first page. Copyrights for third-party components of this work must be honored. For all other uses, contact the Owner/Author.

CHI PLAY EA '19, October 22-25, 2019, Barcelona, Spain (C) 2019 Copyright is held by the owner/author(s). ACM ISBN 978-1-4503-6871-1/19/10. https://doi.org/10.1145/3341215.3356282

\begin{abstract}
Training can be challenging at times, and even more so to users with movement mastery and body awareness issues, like children with sensory-based motor disorder (SBMD). They often experience less enjoyment when engaging with physical activities. In this project, our goal is to support physical training of children with SBMD through the design of playful training activities and technology. Drawing from our observations during a technology-supported circus training course with circus instructors, we identify play potentials that can inspire future technology and activity design. We surface key elements that supported the emergence of play and playfulness, including strategies used by the instructors, and technology features. We discuss how these can be built on in future design iterations.
\end{abstract}

\section{Author Keywords}

Physical Training; Circus; Technology Probes; Children; Sensory Processing Disorder.

\section{CSS Concepts}

- Human-centered computing Empirical studies in interaction design

\section{Introduction}

Physical training has come into focus in HCI research, as a domain in which interactive technology can provide 


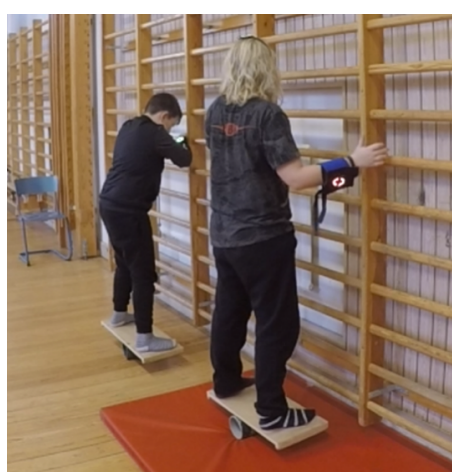

Figure 2: Children balancing on the Rolla-Bolla with support of the gym bars.

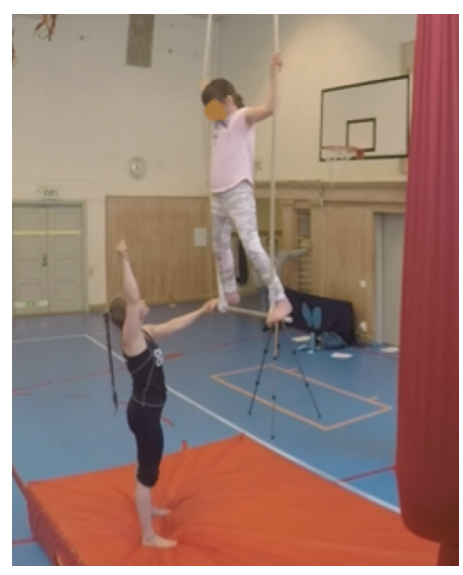

Figure 3. One instructor about exercises on the trapeze: "if you are not scared, it's technically not a difficult thing, anyone with help could do it straightaway, so it's very rewarding for the children" multiple benefits. Works include improving the experience supporting key experiential qualities of training [21], and augmenting the trainees' sensorial capabilities [18]. In the intersection between HCI and games research, work on gamification and playification strategies $[9,12,14]$ aim to increase motivation and support the social experience in training.

In an ongoing project Super Trouper (Figure 1), we investigate how children with mild motor difficulties due to Sensory-based Motor Disorder (SBMD) can be motivated to train, as well as how this training can be made effective through the joint design of training activities and supporting technology. We use a form of open-ended technology solutions, the so called Training Technology Probes (TTPs) (see $[10,23]$ ), which support children and trainers to create a shared understanding of the training activity and goals. However, to create a successful training activity for the target group, we must also consider how it can become engaging. Here, we focus on how physical training can be playified for the target group, based on our observations of trainers and children during an ongoing technology-supported circus training course. We do this through "chasing play potentials" [1] in that course, observing how trainers approach circus training and how technology was used and appropriated by them and the children towards creating a playful, engaging, and empowering activity.

\section{Domain}

Sensory-Based Motor Disorder

Sensory-based Motor Disorder (SBMD) [38] involves a range of motor challenges, many of which are related to issues access and control of the proprioceptive senses. It includes difficulties with balance and postural control; sense of movement, speed, or force; and motor planning, coordination, and execution [38] While these issues are considered common, many children are never diagnosed and hence never receive treatment [25]. Children with SBMD often exhibit low levels of fitness [20] and suffer obesity more than others [4]. In the age range of 5-10, the gap in motor competence between these and other children also grows rapidly [20] and secondary issues appear and escalate [7]. A consequence of this is that they often lack in motivation to exercise [7]. Researchers have suggested that training activities for the group need to be motivating and fun $[5: 44,13]$. Various playful tools for training have been used in occupational therapy for SMBD $[7,13]$, as a way to create playful and openended sensory experiences, that help children develop their sensory capacities.

\section{Playification}

When activities are designed to evoke playful engagement for serious purposes, they can be thought of as being playified. While games have been extensively used in education and healthcare to support training and well-being [6], intrinsically rewarding experiences need not be games. Just as gamification, playification can re-frame a (training) situation as fun and engaging, but rather than using set challenges and extrinsic rewards, playification allows players to appropriate and adapt the activity to suit their individual and collective play $[12,15,16]$.

Playification can provide a frame and structure to an ongoing activity that makes it playful, intrinsically motivating, and worth engaging with [12]. The approach is closely related to work on designing for open-ended play [24], but the open-ended structures (in our case, the training practice as well as the 


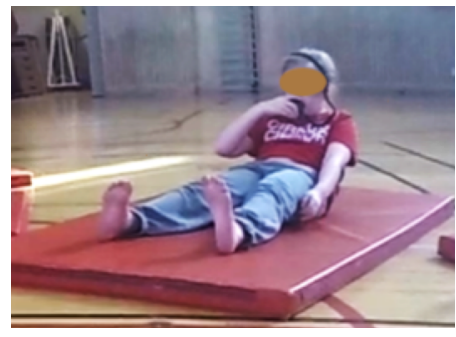

Figure 4: child holding a crunch while blowing onto the Blower TTP, which reacts by lighting up a ring of LEDs (one at a time) as long as blowing continues.

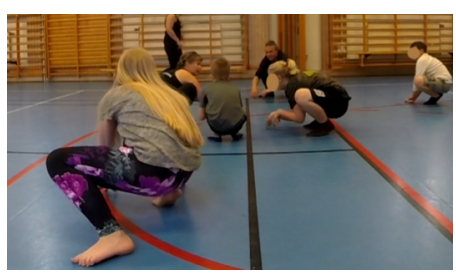

Figure 5: children moving and jumping like frogs.

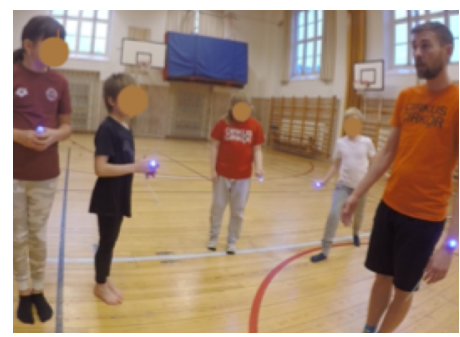

Figure 6: children and instructor with the light bracelet showing blue. Instructor explains the new movement. technology used) have a serious purpose. Playification encourages that this structure be open up and collectively shaped by the participants through transgression and re-negotiation $[2,12]$.

We thus see playification as an overarching strategy that can allow trainers and training children find activities that have both instrumental (training) and hedonic value; that are appropriate and feasible considering the trainee's physical abilities and needs [7], and at the same time fun and worth engaging in the moment [7]. Working within the domain of children with SMBD, these are essential design values $[5,13]$. In order to create playified activities, previous work proposes to first "chase play potentials," that is, to pay close attention to existing or emerging manifestations of play in the context of the targeted activity $[1,12]$. These can then be encouraged and supported through bespoke technology design. This strategy has previously been used successfully in the design of playified rehabilitative exercises for the elderly [12], indicating the potential of "chasing play" in training activities.

\section{Circus Training}

As a practice and training form, circus training exhibits several qualities that makes it particularly useful for the purpose of playful SMBD training $[8,19]$. Firstly, circus training is varied and supports a rich palette of training goals [3]. More importantly, circus training is consonant with playification [12] in that it is performed in a social context but almost entirely without competitive aspects, fostering a sense of relatedness while avoiding competition and scoring. A part of the circus training is that every performer or performance group must develop their own 'act' [3]. Hence, training is individualized from start and focused on building the confidence of trainees in their own capabilities.

Circus training is also spectacular, allowing the children to feel that they are doing something special [8]. While circus acts are difficult to perform, simple tricks can already appear to be grand and spectacular due to the performative nature of circus [3].

\section{Super Trouper, a circus training course}

The training course was organized in collaboration with Cirkus Cirkör, a well- known New Circus company in Sweden that runs training courses for children and adults of all abilities. We recruited a group of seven children, aged 9-12, exhibiting motor issues consonant with SBMD, as established through a pre-screening questionnaire distributed to their parents.

At the time of writing, together with 3 experienced circus pedagogues we have run a total of three courses, each consisting of six training sessions with the children. The first course was organized as a field study without technology (only the last session included preliminary, very open and exploratory prototypes); in the second and the third technology was included throughout. We conducted an extended iterative design process in parallel to the courses, refining both the training practice and the supporting technology to become accessible and fun for the target group. Ideation activities with the children happened in all three courses, and have been seamlessly integrated with training sessions. Separate bodystorming sessions have been held with the trainers [11].

The technology design was primarily built to help trainers and children in their training goals, which has 

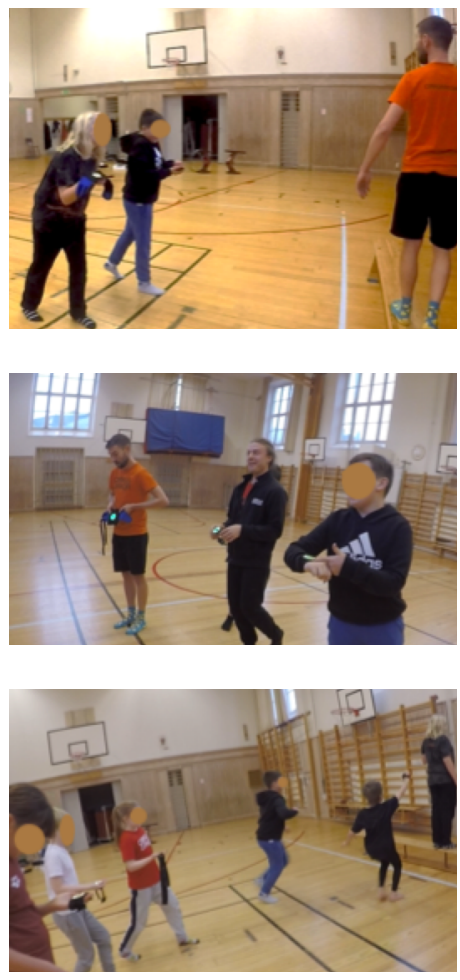

Figure 7: Video capture from the warm-up game of Statues, played with technology been the focus of our prior work [10]. However, an important design goal has been supporting playfulness. Here, we revisit the data gathered throughout the three courses and surface the play potentials emerging from the training practice and use of technology. The analysis is primarily based on observational data, gathered through videos of the training sessions. We also draw from our recurring interviews with the instructors and the children, which were conducted at the end of each training session.

\section{Results}

Throughout our observations, we saw play emerging in both expected and unexpected ways, and for different reasons. Two aspects stood out for how they inspire the future re-design of technology-supported training activities that foster playfulness and play engagement.

Trainer's Strategies to Support Playfulness

Co-existing alternatives. The trainers would always present circus exercises with multiple exercise variations of diverse and varied challenges (what might be challenging for one child would be easy for another). These were creative and expressive variations that conserved the spirit of prowess and awe present in circus acts. For example: balancing on the Rolla-Bolla (Figure 2) with different kinds of support (gym bars, a spotter, nothing); or balancing different kinds of objects (from a feather, to a club, or a plate on a stick). Providing choices also resonates with the circus performers' ethos of finding your own unique way of doing something, of which the children were often reminded. This framed their variations as opportunities to create something special, individual and worth admiring; rather than a same bland exercise that they all needed to do in one way or another. By encouraging the children to individualize their challenges, trainers also encouraged their playful exploration of training activities and their own strengths and challenges.

Supporting the joy of movement. While circus disciplines are highly technical, the instructors focused mostly on letting the children explore and enjoy the circus exercises than on achieving accurate performances. The instructors reflected on the importance of enjoying moving and feeling empowered while moving, and the impact this had on the children's engagement. Most of them have in common a certain shyness, hesitation, and general lack of confidence when approaching movement, physical challenges, and exercise. Hence, discovering the joy to move alone and together is not only a beneficial strategy for SMBD training, but a prerequisite for ensuing training work.

Celebration. Instructors emphasized culmination moments during or after an exercise, e.g. when the child finished passing the tight wire, or when they stood up on the trapeze (Figure 3), something which we came to call the "Ta daa!" moments. They cheered the children while engaged in a challenging activity; applauded them when they showed engagement, focus and effort; praised aspects they were particularly good at during an activity; and complimented them in those disciplines or exercises at which they excelled. The instructors also made sure to include what they called "rewarding exercises": exercises where the technical difficulty is not high, but the result looks majestic, like standing on the trapeze (Fig. 3). The celebration of success meant sometimes encouraging trying and failing at things that went beyond the children's comfort zone, something we see as particularly important with the target group. Celebrating success 
The Game of Statues. This warm-up game was a variation of the popular children's game Statues, wherein children need to reach a curator far from their starting line. They can advance while the curator counts down with their eyes shut, but need to freeze when the countdown is over. The movement probe was used to distinguish between different movement paces (green indicating constant and fluent movements; red for very jerky movements). The technology helped the curator penalize players that stopped suddenly and too close to the end of the countdown (would show a red color; See Fig.7). Since the group understood how the TTP worked they started to "collectively" negotiate potential cheating strategies, such as allowing not stopping at all (even during "frozen" times) if the device was kept in green. This became preferred winning strategy and introduced an interesting movement challenge for the children. and embracing failure are also essential components in game design [6] and in this sense, the instructors implemented a form of gamified training.

Continuous challenge and scaffolding. Instructors recurrently presented the children with new challenges, often building on others they had just engaged with. These were adapted to fit the skills of the child and their interest. Exercise challenges were articulated through inviting prompts such as: "what if...?" "How about...?" "Now, let's..." usually following a positive comment: "Great! Next, try..." We noted that instructors used this strategy to present new variations and exercises but also as a way to avoid overt corrections, articulating them as new challenges.

\section{Technology Aspects Supporting Playfulness}

\section{Technology providing a shared frame of}

reference. The technology training prototypes provide external cues about proprioceptive information of the wearer (e.g. alignment, and orientation of body parts, movement pace, etc.). Since these are accessible both to trainers and children, they provide a shared frame of reference [22]. This design approach was primarily intended to support the training activity. It supported communication between instructor and children, providing the former with cueing tools, and helped both understand, and refer to exercise goals and potential issues. In the videos, we noted how this shared frame also supported play activities [10]. These were creatively invented both by children and trainers. One example is the game Statues, which was adapted to use one of the TTPs (sidebar and Figure 7).

Playful exploration of versatile tools. The introduction of technology led to a lot of playful exploration of its potentials, both within training activities and in adjacent play activities initiated by the children when idling. The same thing happened with some of the circus training equipment and was something the trainers very often sought to inspire, through making a range of training equipment available to the children at the same time. While such playful engagement is likely to emerge at the first encounter with any tool or technology, it survives the novelty effect only if the tool is sufficiently versatile to support open-ended play [24]. Most of the TTPs have continued to invite playful exploration throughout the two courses where they have been used, as have some of the circus training tools, most notably the juggling tools.

Mini-challenges. The instructors would very often use the technology probes as a tool in their continuous strive for new challenges and scaffolding exercises. For example, when wearing Blower TTP [10] while doing crunches, the instructors challenged the children to hold the crunch while blowing, trying to "light up as many lights as possible" (Figure 4). But children would very often invent these challenges themselves, e.g.: one child placed the Movement TTP [10] (which reacts to acceleration, beeping with more frequency as it increases) also while performing a crunch, and told us they were trying to perform it without triggering the sound (by keeping a constant pace).

Warm-up games. At the start of each session, the trainers would run at least one, and sometimes several, warm-up games. These were joint exercises intended to create focus, bodily movement, and group cohesion among the participants, and are common in a range of training practices [8]. The TTPs found their way also into these warm-up games, such as in Statues (Fig. 7 
Key design strategies for the design of technology to support playified training

- Providing visual and audio cues to the whole group rather than just the individual using the technology. This creates a shared, flexible frame for co-creating playful training.

- Design both form and interactivity to spur the children's imagination and fantasy play. This heightens the children's engagement and creative play.

Signaling in-the-moment measures rather than measuring success, through evocative light and sound. This supports continuous challenges and scaffolding and coexisting alternatives. It also supports communicating the 'Ta Daa!' moment, and installs a sense of achievement while deemphasizing failure. and sidebar). One warm-up game involved moving like different animals (Figure 5 and 6 ). A bracelet with a LED light whose color changed with a remote control, built on that initial warm-up game: animals were color coded, and everyone had to walk accordingly to their color. A curator holding the remote control changed the color of everyone or of individual children. Different children were moving in different ways at the same time, and there was some degree of control over movement changes both by the curator and the children (e.g. children farther from the control remote were not affected by it, which they soon realized and leveraged). This resulted in a richer and more engaging game that supported increased focus and excitement.

'Magic' and Pretense play. Sometimes, the technology probes would spur a sense of fantasy and "magic" with the children, something that is shared by much of the ordinary circus equipment. When this happened, it created intense engagement. For example, one child spent the major part of one session pretending to be a superhero, by fastening a Laser light TTP [10] to their hand and trying to "shoot" the laser in a particular direction or at a moving target somewhere else in the room. Later on, the same child told us that it felt like being a superhero: "when I had [the laser] on the hand, [I was like] Ironman!".

Most children were highly motivated by fantasy play. We suspect this to be a particularly important aspect for the target group, and was also how trainers very often would frame the warm-up games.

\section{Discussion and Future Work}

Based on our observations above, we identify some design features of our TTPS, which can be further enhanced in future design work (see side box). The probes were designed to be deliberately simple in functionality and technical implementation; to communicate towards the wearer as well as others (e.g. instructors) and to signal in-the-moment proprioceptive information rather than measuring success [10]. This design strategy is beneficial in playification as it provides the children and instructors with a flexible frame that can be used to create playful challenges. We conclude by reflecting on the tension in balancing playful engagement, with a serious focus on training and challenge, which we observed the trainers striving for since the onset. At times, the children resisted this balance, satisfied with having fun. With the target group, playful engagement must be seen as a beneficial first step that can reshape their perception of training as something that can be fun and worth doing. From this perspective, we have seen how introducing technology often helped towards focused training. It helped the children to maintain focus on their training task [10] and allowed both them and the trainers to create playful challenges. But we have also seen instances when the tools become toys, distracting the children from participating in the training activities, especially when training on their own. In the next phase of the project, these insights will be taken further to focus on how the technology probes can support playful but yet focused engagement in individual training, both in class and at home.

\section{Acknowledgements}

This research is funded by Vetenskapsrådet (award number:2017-04880), which we are thankful to. We thank our super heroes, the children participating in this study; and the amazing Cirkus Cirkör team: Oskar Löfkvist, Katarina Rosen, and Isak Arvidsson. 


\section{References}

1. Ferran Altarriba Bertran, Elena Márquez Segura, Jared Duval, and Katherine Isbister. 2019. Chasing Play Potentials: Towards an Increasingly Situated and Emergent Approach to Everyday Play Design. In Proceedings of the 2019 on Designing Interactive Systems Conference (DIS'19), ACM, 1265-1277.

2. Jon Back, Elena Márquez Segura, and Annika Waern. 2017. Design for Transformative Play. ACM Transactions on Computer-Human Interaction 24 3: 18:1-18:28.

3. Paul Bouissac. 2012. Circus as multimodal discourse: Performance, meaning, and ritual. $A \& C$ Black.

4. John Cairney, J. A. Hay, B. E. Faught, and R. Hawes. 2005. Developmental coordination disorder and overweight and obesity in children aged 9-14 y. International Journal of Obesity 29, 4: 369-372.

5. Jane Case-Smith and Jane Clifford O'Brien. 2013. Occupational therapy for children. Elsevier Health Sciences.

6. Jesper Juul. 2013. The art of failure: An essay on the pain of playing video games. Mit Press.

7. Carol Kranowitz. 2006. The Out-of-Sync Child Has Fun, Revised Edition: Activities for Kids with Sensory Processing Disorder. Penguin.

8. Jill Maglio, Carol McKinstry, and others. 2008. Occupational therapy and circus: potential partners in enhancing the health and well-being of today's youth. Australian Occupational Therapy Journal 55, 4: 287-290.

9. Elena Márquez Segura, Luis Márquez Segura, and Clara López Torres. 2012. PhySeEar Moving yourself to shine and sound in geriatric physiotherapy interventions. International Conference on Pervasive Computing Technologies for Healthcare (PervasiveHealth'12), IEEE, 179182.
10. Elena Márquez Segura, Laia Turmo Vidal, Luis Parrilla Bel, and Annika Waern. 2019. Circus, Play and Technology Probes: Training Body Awareness and Control with Children. In Proceedings of the 2019 on Designing Interactive Systems Conference (DIS'19), ACM, 1223-1236.

11. Elena Márquez Segura, Laia Turmo Vidal, Luis Parrilla Bel, and Annika Waern. 2019. Using Training Technology Probes in Bodystorming for Physical Training. In Proceedings of the 6th International Conference on Movement and Computing (MOCO'19), ACM.

12. Elena Márquez Segura, Annika Waern, Luis Márquez Segura, and David López Recio. 2016. Playification: The PhySeEar Case. In Proceedings of the 2016 Annual Symposium on Computer-Human Interaction in Play (CHIPlay'16), ACM, 376-388.

13. Lucy Jane Miller. 2014. Sensational Kids: Hope and Help for Children with Sensory Processing Disorder. TarcherPerigee.

14. Florian Mueller, Martin R. Gibbs, and Frank Vetere. 2010. Towards understanding how to design for social play in exertion games. In Personal and Ubiquitous Computing 14, 5: 417-424.

15. Scott Nicholson. 2012. A user-centered theoretical framework for meaningful gamification. Games+ Learning+ Society 8, 1: 223-230.

16. Scott Nicholson. 2015. A RECIPE for Meaningful Gamification. In T. Reiners and L.C. Wood, eds., Gamification in Education and Business. Springer International Publishing, 1-20.

17. Scott Nicholson. 2015. A recipe for meaningful gamification. In Gamification in education and business. Springer, 1-20.

18. Stina Nylander, Alex Kent, and Jakob Tholander. 2014. Swing Sound: Experiencing the Golf Swing Through Sound. In CHI'14 Extended Abstracts on Human Factors in Computing Systems (CHI EA'14), ACM, 443-446. 
19. Sonia Sahli, Sameh Ghroubi, Haithem Rebai, M. Chaâbane, A. Yahia, Dominic Pérennou, and Mohammed Habib Elleuch. 2013. The effect of circus activity training on postural control of 5-6year-old children. Science \& Sports 28, 1: 11-16.

20. Nadja Schott, Verena Alof, Daniela Hultsch, and Dagmar Meermann. 2007. Physical fitness in children with developmental coordination disorder. Research quarterly for exercise and sport 78, 5: 438-450.

21. Jakob Tholander and Stina Nylander. 2015. Snot, Sweat, Pain, Mud, and Snow: Performance and Experience in the Use of Sports Watches. In Proceedings of the 33rd Annual ACM Conference on Human Factors in Computing Systems (CHI'15), ACM, 2913-2922.

22. Laia Turmo Vidal, Elena Márquez Segura, Christopher Boyer, and Annika Waern. 2019.

Enlightened Yoga: Designing an Augmented Class with Wearable Lights to Support Instruction. In
Proceedings of the 2019 on Designing Interactive Systems Conference (DIS'19), ACM, 1017-1031.

23. Laia Turmo Vidal, Elena Márquez Segura, Luis Parrilla Bel, and Annika Waern. 2019. BalBoa: A Balancing Board for Handstand Training. In $\mathrm{CHI}^{\prime} 19$ Extended Abstracts Human Factors in Computing Systems (CHI EA'19), ACM, LBW1414:1LBW1414:6.

24. Linda de Valk, Tilde Bekker, and Berry Eggen. 2013. Leaving room for improvisation: towards a design approach for open-ended play. In Proceedings of the 12th International Conference on Interaction Design and Children (IDC'13), ACM 92-101.

25. Nathan Watemberg, Nilly Waiserberg, Luba Zuk, and Tally Lerman-Sagie. 2007. Developmental coordination disorder in children with attentiondeficit-hyperactivity disorder and physical therapy intervention. Developmental Medicine \& Child Neurology 49, 12: 920-925. 